\title{
Atrioventricular block after acute myocardial infarction and its association with other clinical parameters in Pakistani patients: an institutional perspective
}

\author{
Kashif Ali Hashmi ${ }^{1}$, Amir Shehzad ${ }^{1}$, Atif Ali Hashmi ${ }^{2}$ and Amir Khan ${ }^{3^{*}}$ (])
}

\begin{abstract}
Objectives: Conduction defects complicating acute myocardial infarction are frequently associated with increased morbidity and mortality. As frequency of this complication has not been widely studied in our population, therefore in this study we aimed to evaluate the frequency of complete atrioventricular block in patients with acute ST segment elevation myocardial infarction and its association with other clinical parameters.

Results: The mean age of the patients was $50.55 \pm 6.72$ years at the time of MI. There were 147 (82.1\%) males and 32 (17.9\%) females. There were 83 (46.4\%) patients having hypertension, 61 (34.1\%) diabetes mellitus, 75 (41.9\%) smokers, 75 (41.9\%) patients having positive family history, 11 (6.1\%) having dyslipidemia, and 73 (40.8\%) obese patients in this study. The Frequency of complete atrioventricular (AV) block in acute ST segment elevation myocardial infarction was found to be $7.3 \%$, and no association with any other clinical factor was found which could predict this condition according to results of our study. Therefore, protocols should be designed in our routine clinical practice to deal with such a life threatening condition.
\end{abstract}

Keywords: Myocardial infarction, ST segment elevation myocardial infarction, Complete atrioventricular block

\section{Introduction}

Acute myocardial infarction (AMI) is a grave clinical condition and remains a leading cause of mortality all over the world. It occurs due to loss of blood supply to part of the heart muscle resulting in tissue injury as a result of oxygen deprivation [1]. Myocardial infarction is considered part of a spectrum referred to as acute coronary syndrome (ACS). The ACS continuum represents ongoing myocardial ischemia or injury and it consists of unstable angina, non-ST-segment elevation myocardial infarction (NSTEMI), and ST-segment elevation myocardial infarction (STEMI) [2]. Worldwide, more than 3 million people suffer from STEMIs and 4 million develop

\footnotetext{
*Correspondence: dramirkhan04@gmail.com

${ }^{3}$ Kandahar University, Kandahar, Afghanistan

Full list of author information is available at the end of the article
}

NSTEMIs a year [3]. STEMIs occur about twice as often in men as women [4].

The presence of conduction defects complicating acute myocardial infarction (MI) is relatively frequent and is associated with increased short and long term mortality rates [5].Atrioventricular (AV) block is a common complication of acute Myocardial Infarction (MI). In pre-thrombolytic era, high (second or third degree) AV block was seen in patients presenting with acute MI [6]. Although, the advent of thrombolytic therapy has substantially decreased the mortality associated with acute MI, the incidence of AV block persists [7]. Bhalli MA et al. [8] has found complete atrioventricular (AV) block in $8.1 \%$ patients presenting with acute myocardial infarction.

The rationale of this study is to evaluate the frequency of complete atrioventricular (AV) block in patients with acute ST segment elevation myocardial infarction 
(STEMI). As AV block along with acute myocardial infarction is associated with higher morbidity and mortality, so the results of this study will help the clinicians to design a protocol and make some clinical recommendations in our routine practice guidelines for management of these high risk group patients in order to reduce the morbidity and mortality of the community.

\section{Main text}

It was a descriptive cross-sectional study conducted at department of cardiology Chaudhry Pervaiz Elahi Institute of Cardiology, Multan from January 2015 till July 2016 over a period of 1.5 years. All those patients diagnosed on admission as acute ST segment elevation Myocardial infarction (ST segment elevation of $>1 \mathrm{~mm}$ in limb leads and $>2 \mathrm{~mm}$ in precardial leads) were included in the study. Total number of 179 patients, fulfilling the inclusion criteria was selected after taking permission from ethical review committee and informed written consent to be included in the study from each patient. In all patients ECG was done which was evaluated by the consultant cardiologist (at least post fellowship experience of 5 years) for presence or absence of AV block in these particular patients. All this data was recorded on a predesigned proforma.

\section{Methods}

Statistical analysis was performed using SPSS version 20.0. Mean and standard deviation were calculated for quantitative variables like age and duration of presentation. Frequency and percentage was calculated for qualitative variables like gender, obesity and complete AV block, smoker, hypertension, dyslipidemia, diabetes mellitus and family history. Effect modifiers like age, gender, duration of presentation, obesity, smoker, hypertension, dyslipidemia, family history of IHD and diabetes mellitus were controlled through stratifications. Post-stratification Chi square test was applied to see their effects on the outcome and $P$ value $\leq 0.05$ was considered as significant.

\section{Results}

A total number of one hundred and seventy-nine (179) patients with ST segment elevation Myocardial Infarction were included in this study. The mean age of the patients was $50.55 \pm 6.72$ years at the time of MI. There were 147 $(82.1 \%)$ males and $32(17.9 \%)$ females in this study. The mean duration of presentation to hospital after myocardial infarction was $9.05 \pm 5.14 \mathrm{~h}$. There were 83 (46.4\%) patients having hypertension, 61 (34.1\%) diabetes mellitus, 75 (41.9\%) smokers, 75 (41.9\%) patients having positive family history, 11 (6.1\%) having dyslipidemia, and 73 $(40.8 \%)$ obese patients in this study. Complete atrioventricular block was found in 13 (7.3\%) patients and shown in Table 1. No significant association was found between presence of $\mathrm{AV}$ block and various clinical parameters studied including age, gender, smoking, hypertension, diabetes, dyslipidemia, family history, obesity and duration of symptoms (Table 2).

Out of 179 patients, 38 (21.2\%) patients presented within $12 \mathrm{~h}$ of onset of symptoms and therefore received thrombolytic therapy or angioplasty with stent placement. On the other hand remaining 141 (78.7\%) patients presented to the hospital after $12 \mathrm{~h}$ of onset of symptoms and therefore received only conservative management including beta blockers, morphine and statins. All the 13 patients who developed AV block were those who received only conservative therapy. Among 13 patients who developed AV block, 9 patients (69.2\%) had placement of permanent pacemakers; on the other hand, 4 patients $(30.4 \%)$ received conservative management including antibiotic treatment or withdrawal of drugs. The duration of study follow up was

Table 1 Demographic and clinical features of patients involved in the study

\begin{tabular}{|c|c|}
\hline & $\mathrm{N}(\%)$ \\
\hline $\mathrm{Age}^{\mathrm{a}}$ & $50.55 \pm 6.72$ \\
\hline Duration of presentation ${ }^{a}$ & $9.05 \pm 5.14$ \\
\hline \multicolumn{2}{|l|}{ Gender } \\
\hline Male & $147(82.1)$ \\
\hline Female & $32(17.9)$ \\
\hline \multicolumn{2}{|l|}{ Hypertension } \\
\hline Present & $83(46.4)$ \\
\hline Absent & $96(53.6)$ \\
\hline \multicolumn{2}{|l|}{ Diabetes } \\
\hline Present & $61(34.1)$ \\
\hline Absent & $118(65.9)$ \\
\hline \multicolumn{2}{|l|}{ Smoking } \\
\hline Present & 75 (41.9) \\
\hline Absent & $104(58.1)$ \\
\hline \multicolumn{2}{|l|}{ Family history } \\
\hline Present & $41(22.9)$ \\
\hline Absent & $138(77.1)$ \\
\hline \multicolumn{2}{|l|}{ Dyslipidemia } \\
\hline Present & $11(6.1)$ \\
\hline Absent & $168(93.9)$ \\
\hline \multicolumn{2}{|l|}{ Obesity } \\
\hline Present & $73(40.8)$ \\
\hline Absent & $106(59.2)$ \\
\hline \multicolumn{2}{|l|}{ Complete AV block } \\
\hline Present & $13(7.3)$ \\
\hline Absent & $166(92.7)$ \\
\hline
\end{tabular}

a Mean \pm SD 
Table 2 Co-relation of atrioventricular block with other clinical features

\begin{tabular}{|c|c|c|c|}
\hline & \multicolumn{2}{|c|}{$\begin{array}{l}\text { Complete AV block } \\
\mathrm{N}\end{array}$} & \multirow[t]{2}{*}{$P$ value } \\
\hline & Present & Absent & \\
\hline \multicolumn{4}{|c|}{ Age group (years) } \\
\hline $30-48$ & 5 & 56 & \multirow[t]{3}{*}{$0.39^{*}$} \\
\hline $49-54$ & 6 & 55 & \\
\hline$>55$ & 2 & 55 & \\
\hline \multicolumn{4}{|l|}{ Gender } \\
\hline Male & 10 & 137 & \multirow[t]{2}{*}{$0.61^{*}$} \\
\hline Female & 3 & 29 & \\
\hline \multicolumn{4}{|l|}{ Smoking } \\
\hline Present & 5 & 70 & \multirow[t]{2}{*}{$0.794^{*}$} \\
\hline Absent & 8 & 96 & \\
\hline \multicolumn{4}{|c|}{ Hypertension } \\
\hline Present & 5 & 78 & \multirow[t]{2}{*}{$0.55^{*}$} \\
\hline Absent & 8 & 88 & \\
\hline \multicolumn{4}{|l|}{ Diabetes } \\
\hline Present & 3 & 58 & \multirow[t]{2}{*}{$0.38^{*}$} \\
\hline Absent & 10 & 108 & \\
\hline \multicolumn{4}{|c|}{ Dyslipidemia } \\
\hline Present & 1 & 10 & \multirow[t]{2}{*}{$0.81^{*}$} \\
\hline Absent & 12 & 156 & \\
\hline \multicolumn{4}{|c|}{ Family history } \\
\hline Present & 1 & 40 & \multirow[t]{2}{*}{$0.17^{*}$} \\
\hline Absent & 12 & 126 & \\
\hline \multicolumn{4}{|l|}{ Obesity } \\
\hline Present & 4 & 69 & \multirow[t]{2}{*}{$0.44^{*}$} \\
\hline Absent & 9 & 97 & \\
\hline \multicolumn{4}{|c|}{ Duration of presentation (h) } \\
\hline $1-6$ & 2 & 62 & \multirow[t]{3}{*}{$0.22^{*}$} \\
\hline $7-10$ & 7 & 56 & \\
\hline $11-24$ & 4 & 48 & \\
\hline
\end{tabular}

Chi square test was applied

$P$ value $\leq 0.05$ considered as significant

* Not significant at 0.05 level

only during the hospital stay, therefore long term outcome couldn't be evaluated.

Complete atrioventricular (AV) block is a common complication of acute ST segment elevation myocardial infarction. There is an increased risk for the development of complete AV block in patients suffering from STEMI as compared to patient's non-STEMI $[9,10]$. The exact mechanism for the development of complete AV block still remains unclear. The 1st one may be cardio-inhibitory reflex originating from vagal reflexes in the ischemic left ventricular infero-posterior wall [11], the 2nd one is the AV nodal ischemia [12,13].
Previous studies have shown that acute myocardial infarction complicated by complete AV block have a high killip class and increased risk of in hospital complications e.g. cardiogenic shock, intra-ventricular arrhythmias, and increased risk of in hospital mortality [14-16]. Experience with complete AV block in patients with STEMI have shown that $\mathrm{CHB}$ respond to atropine and isoproterenol in the vast majority of cases and usually it does not require even temporary pacing and almost never implantation of permanent pacemakers [17, 18]. However current guidelines have recommended that temporary pacing is indicated for symptomatic bradyarrythmias unresponsive to medical treatment [19].

The rate complete AV block after STEMI varies from 2.9 to $12.8 \%$. In Pakistan the rate of complete AV block after STEMI have been reported to be $2.9-11.8 \%$ [20-22], this rate is less as compared to the other studies in the rate is reported to be $9.1-12.8 \%[23,24]$. In present study the rate of complete AV block was $7.3 \%$ in patients of STEMI. In our study, mean age of the patients was $50.55 \pm 6.72$ years at the time of MI but in the study of Iqbal et al. the main age of the patients was $58.88 \pm 12.5$ years that was higher as compared to the patients of our study [20].

We done stratification of various confounder variables e.g. age, gender, diabetes, hypertension, smoking, dyslipidemia and duration of presentation after MI to see is there any effect of these on the development of complete AV block after MI but we do not found any significant effect of these variables and the incidence of complete AV block remained same in all these groups.

\section{Limitations}

The main limitation of the study was that this was a single institution study in which we found the frequency of complete atrioventricular (AV) block after acute ST segment elevation myocardial infarction to be $7.3 \%$. However, as this is a major center of cardiovascular diseases in the province and represents patient population from both rural and urban areas, therefore we suggest that, protocols should be designed in our routine clinical practice to deal with such a life threatening condition.

\section{Abbreviations}

AV block: complete atrioventricular block; MI: myocardial infarction.

\section{Authors' contributions}

$\mathrm{KAH}$ and AS: main author of manuscript, have made substantial contributions to conception and design of study. AAH and AK have been involved in requisition, analysis of the data and gave final approval and revision of the manuscript. All authors read and approved the final manuscript. 


\section{Author details}

${ }^{1}$ Chaudhry Pervaiz Elahi Institute of Cardiology Multan, Multan, Punjab, Pakistan. ${ }^{2}$ Liaquat National Hospital and Medical College, Karachi, Sindh, Pakistan.

${ }^{3}$ Kandahar University, Kandahar, Afghanistan.

\section{Acknowledgements}

We gratefully acknowledge all staff members of Cardiology Department, Cardiology Institute, Pakistan for their help and cooperation.

\section{Competing interests}

The authors declare that they have no competing interests.

\section{Availability of data and materials}

The datasets used and analyzed during the current study are available from the corresponding author on request.

\section{Consent to publish}

Not applicable.

\section{Ethics approval and consent to participate}

Ethics committee of PIMS, Islamabad, Punjab, Pakistan approved the study. Written informed consent was obtained from the patients for the participation.

\section{Publisher's Note}

Springer Nature remains neutral with regard to jurisdictional claims in published maps and institutional affiliations.

Received: 30 March 2018 Accepted: 11 May 2018

Published online: 21 May 2018

\section{References}

1. Hamm CW, Bassand JP, Agewall S, Bax J, Boersma E, Bueno H, et al. ESC Guidelines for the management of acute coronary syndromes in patients presenting without persistent ST-segment elevation: the Task Force for the management of acute coronary syndromes (ACS) in patients presenting without persistent ST-segment elevation of the European Society of Cardiology (ESC). Eur Heart J. 2011;32(23):2999-3054.

2. Bonaca MP, Wiviott SD, Braunwald E. American College of Cardiology/ American Heart Association/European Society of Cardiology/World Heart Federation Universal Definition of Myocardial Infarction Classification System and the Risk of Cardiovascular Death: observations from the TRITON-TIMI 38 trial. Circulation. 2012;125(4):577-83.

3. White HD, Chew DP. Acute myocardial infarction. Lancet. 2008;372(9638):570-84.

4. O'Gara PT, Kushner FG, Ascheim DD, Casey DE Jr, Chung MK, de Lemos JA, et al. 2013 ACCF/AHA guideline for the management of ST-elevation myocardial infarction: a report of the American College of Cardiology Foundation/American Heart Association Task Force on Practice Guidelines. Circulation. 2013;127(4):362-425

5. Cheng S, Keyes MJ, Larson MG. Long-term outcomes in individuals with prolonged PR interval or first-degree atrioventricular block. JAMA. 2009:301(24):2571-7.

6. Ho KW, Koh TH. Complete atrioventricular block complicating acute anterior myocardial infarction can be reversed with acute coronary angioplasty. Ann Acad Med Singap. 2010;39:254-7.
7. Grajek S, Lesiak M, Araszkiewicz A, Pyda M, Skorupski W, Grygier M, et al Short and longterm mortality in patients with ST-elevation myocardial infarction treated with different therapeutic strategies. Kardiol Pol. 2008;66:154-63.

8. Bhalli MA, Khan MQ, Samore NA, Mehreen S. Frequency and clinical outcome in conduction defects in acute myocardial infarction. J Ayub Med Coll Abbottabad. 2009:21(3):32-7.

9. Gang UJ, Hvelplund A, Pedersen S, Iversen A, Jøns C, Abildstrøm SZ, et al. High-degree atrioventricular block complicating ST-segment elevation myocardial infarction in the era of primary percutaneous coronary intervention. Europace. 2012;14(11):1639-45.

10. Hwang IC, Seo WW, Oh IY, Choi EK, Oh S. Reversibility of atrio-ventricular block according to coronary artery disease: results of a retrospective study. Korean Circ J. 2012;42(12):816-22.

11. Kosuge M, Kimura K, Ishikawa T, Nakatogawa T, Saito T, Okuda J, et al. Clinical features of patients with reperfused inferior wall acute myocardial infarction complicated by early complete atrioventricular block. Am J Cardiol. 2001:88(10):1187-91.

12. Adgey AA, Geddes JS, Mulholland HC, Keegan DA, Pantridge JF. Incidence, significance, and management of early bradyarrhythmia complicating acute myocardial infarction. Lancet. 1968;2(7578):1097-101.

13. Webb SW, Adgey AA, Pantridge JF. Autonomic disturbance at onset of acute myocardial infarction. Br Med J. 1972;3(5818):89-92.

14. Berger PB, Ryan TJ. Inferior myocardial infarction. High-risk subgroups. Circulation. 1990;81(2):401-11.

15. Rotman M, Wagner GS, Wallace AG. Bradyarrhythmias in acute myocardial infarction. Circulation. 1972:45(3):703-22.

16. Aplin $M$, Engstrøm $T$, Vejlstrup NG, Clemmensen P, Torp-Pedersen C, Køber L, TRACE Study Group. Prognostic importance of complete atrioventricular block complicating acute myocardial infarction. Am J Cardiol. 2003:92(7):853-6.

17. Ho KW, Koh TH, Wong P, Wong SL, Lim YT, Lim ST, Hsu LF. Complete atrioventricular block complicating acute anterior myocardial infarction can be reversed with acute coronary angioplasty. Ann Acad Med Singap. 2010;39(3):254-7.

18. Lee SN, Hwang YM, Kim GH, Kim JH, Yoo KD, Kim CM, et al. Primary percutaneous coronary intervention ameliorates complete atrioventricular block complicating acute inferior myocardial infarction. Clin Interv Aging. 2014;9:2027-31.

19. Sclarovsky S, Strasberg B, Hirshberg A, Arditi A, Lewin RF, Agmon J. Advanced early and late atrioventricular block in acute inferior wall myocardial infarction. Am Heart J. 1984;108:19-24.

20. Iqbal MA, Hadi A, Ahmad F, Shah ST, Haq MR, lqbal A, et al. Conduction disturbances in patients with acute anterior wall myocardial infarction and in-hospital outcomes. Pak Heart J. 2014;47(3):156-61.

21. Bhalli MA, Khan MQ, Samore NA, Mehreen S. Frequency and clinical outcome in conduction defects in acute myocardial infarction. J Ayub Med Coll Abbottabad. 2009;21(3):32-7.

22. Bilal HB, Sultan J, Hassan K, Ovais K, Majeed I. Heart blocks as predictors of mortality in acute myocardial infarction. J Rawal Med Coll. 1999;3(12):13-6.

23. Hindman MC, Wagner GS, JaRo M, Atkins JM, Scheiman MM, DeSanctis RW, et al. The clinical significance of bundle branch block complicating acute myocardial infarction, 1: clinical characteristics, hospital mortality, and one-year follow-up. Circulation. 1978;58:679-88.

24. Kostuk WJ, Beanlands DS. Complete heart block associated with acute myocardial infarction. Am J Cardial. 1970;26:380-4. 